\title{
Evaluation of Quality of Life in HIV-Infected Children and Children with Cancer
}

\section{Ana Karla Buczynski ${ }^{1^{*}}$, Anna Thereza Thomé Leão ${ }^{2}$ and Ivete Pomarico Ribeiro de Souza ${ }^{1}$}

${ }^{1}$ Department of Pediatric Dentistry and Orthodontics, School of Dentistry, Federal University of Rio de Janeiro, Rio de Janeiro, Brazil

${ }^{2}$ Department of Periodontics, School of Dentistry, Federal University of Rio de Janeiro, Rio de Janeiro, Brazil

${ }^{*}$ Corresponding author: Dr. Ana Karla Buczynski, DDS, MSD, PHD, Department of Pediatric Dentistry and Orthodontics, School of Dentistry, Federal University of Rio de Janeiro, Rio de Janeiro, Brazil, Tel: +55-21-993338080; E-mail: anakarlab@gmail.com

Rec Date: Oct 27, 2014; Acc Date: Dec 30, 2014; Pub Date: Jan 05, 2015

Copyright: ( 2015 Buczynski AK et al. This is an open-access article distributed under the terms of the Creative Commons Attribution License, which permits unrestricted use, distribution, and reproduction in any medium, provided the original author and source are credited.

\begin{abstract}
Background: The presence of a chronic illness in childhood, such as HIV infection and cancer, can affect the quality of life and oral health-related quality of life negatively. This work aims to evaluate the quality of life and the oral health-related quality of life of HIV-infected children and children with cancer and compare the results with children without systemic chronic disease.
\end{abstract}

Methods: The Autoquestionnaire Qualité de Vie Enfant Imagé (AUQEI) and the short version of Child Perception Questionnaire (short-CPQ $11-14$ ) were applied to 82 HIV-infected children, 31 children with cancer and 112 children without systemic disease aged between 11 and 14 years old. All children were examined oral for the presence of any oral health problems. The Kruskal- Wallis test was used to compare the mean scores obtained by the groups.

Results: HIV-infected children (AUQEI=49.93; short-CPQ $11-14=6.29$ ) and children with cancer (AUQEI=50.45; short-CPQ $\left.Q_{11-14}=6.81\right)$ showed a lower quality of life $(p=0.011)$ and oral-health-related quality of life $(p=0.043)$ when compared to children without systemic disease (AUQEI=52.18; short-CPQ $11-14=3.82$ ).

Conclusion: The quality of life and the oral health-related quality of life of children are negatively affected by the HIV-infection and cancer and oral health problems.

Keywords: Child; HIV infections; Neoplasms; Oral health; Quality of life

\section{Introduction}

From the moment a chronic illness is diagnosed in childhood there is a profound psychological impact on the quality of life of the patients and their relatives, on family and social relationships, and on role functioning [1]. Moreover, children and adolescents with a chronic condition face several challenges. They must cope with the unique demands of their chronic condition, along with the developmental tasks associated with their particular age group [2]. Among the chronic diseases in childhood, HIV infection and cancer have become more relevant due to the increased survival with the introduction of new therapies and diagnostic methods, changing the diseases from lethal and acute to chronic and subacute $[3,4]$.

The increased survival of patients with chronic diseases has brought a more qualitative approach to care, seeking a multidisciplinary approach, with greater emphasis on their quality of life $[5,6]$. These strategies allow health professionals to try to prevent or lessen the psychosocial consequences that these patients have to face. Thus, dentistry has a fundamental role, since both HIV infection and cancer can lead to occurrence of oral health problems such as caries disease, gingival disease and other oral lesions [7]. Such problems can be a direct consequence of the disease, or indirect through changes in salivary function, frequent intake of medication, high calorie diet and inadequate oral hygiene habits.
Oral health problems can cause pain, discomfort, difficulty in chewing, decreased appetite, decreased weight, insomnia, poor selfesteem, change in behavior, low school performance, increasing number of school absences and activity restrictions [8,9]. All these issues can affect functional, physical, psychological and social performance, leading to a significant impact on quality of life. Thus, the null hypothesis to be tested is that quality of life and oral health related quality of life of HIV-infected children and children with cancer are similar to those children without disease.

\section{Methods}

This cross-sectional study selected 82 children and the inclusion criteria comprehended definitive diagnosis to HIV infection for at least 3 months. Thirty-one children in treatment for at least 3 months were selected with presence of cancer, as the inclusion criteria. And 112 children whose parents reported no chronic systemic infection, which was confirmed after checking medical records, were also selected. All children were aged between 11 and 14 years old and were conveniently selected when they attended medical appointments at two hospitals in Rio de Janeiro, Brazil. The exclusion criteria consisted of children less than 10 years old and older than 15 years old and inconsistent answers at the moment of questionnaire filling. The experimental period was two years. Each caregiver signed an informed consent form for inclusion in this survey. The research was initiated after approval of the local Ethics Committee.

We had no dropouts and after obtaining the basic data of the child, the questionnaire of Brazilian Economical Classification Criteria 
Citation: Buczynski AK, Leão ATT, de Souza IPR (2015) Evaluation of Quality of Life in HIV-Infected Children and Children with Cancer.

Page 2 of 7

(Associação Brasileira de Empresas de Pesquisa) was applied. This characterized families in terms of economic class into 7 catorgories:
$\mathrm{A} 1, \mathrm{~A} 2, \mathrm{~B} 1, \mathrm{~B} 2, \mathrm{C} 1, \mathrm{C} 2, \mathrm{D}$ and $\mathrm{E} . \mathrm{A} 1$ is the highest economic class and E the lowest.

\begin{tabular}{|c|c|c|c|c|}
\hline & HIV-infected children & Children with cancer & No-disease children & $p$-value \\
\hline Mean age & $12.02( \pm 1.06)$ & $12.45( \pm 1.15)$ & $12.48( \pm 0.99)$ & $p=0.010^{a}$ \\
\hline \multicolumn{5}{|l|}{ Children gender } \\
\hline Male & $36(43.9 \%)$ & $19(61.3 \%)$ & $64(57.1 \%)$ & \multirow[t]{2}{*}{$p=0.114$} \\
\hline Female & $46(56.1 \%)$ & $12(38.7 \%)$ & $48(42.9 \%)$ & \\
\hline \multicolumn{5}{|l|}{ Caregiver ocupation } \\
\hline Employed/Retired & $40(48.8 \%)$ & $6(19.4 \%)$ & $57(50.9 \%)$ & \multirow[t]{3}{*}{$p=0.003^{a}$} \\
\hline Autonomic & $17(20.7 \%)$ & $9(29.9 \%)$ & $34(30.4 \%)$ & \\
\hline Unemployed & $25(30.5 \%)$ & $16(51.6 \%)$ & $21(18.8 \%)$ & \\
\hline \multicolumn{5}{|l|}{ Caregiver instruction } \\
\hline No schooling & $7(8.5 \%)$ & 0 & $4(3.6 \%)$ & \multirow[t]{4}{*}{$p=0.009^{a}$} \\
\hline Preschool or Elementary school & $57(69.5 \%)$ & $13(41.9 \%)$ & $73(65.2 \%)$ & \\
\hline High school & $15(18.3 \%)$ & $14(12.9 \%)$ & $30(26.8 \%)$ & \\
\hline College & $3(3.7 \%)$ & $4(12.9 \%)$ & $5(4.5 \%)$ & \\
\hline \multicolumn{5}{|l|}{ Economic classification } \\
\hline $\mathrm{A} 1 / \mathrm{A} 2 / \mathrm{B} 1$ & $2(2.4 \%)$ & $3(9.7 \%)$ & $3(2.7 \%)$ & \multirow[t]{3}{*}{$p=0.000^{a}$} \\
\hline $\mathrm{B} 2 / \mathrm{C} 1 / \mathrm{C} 2$ & $54(65.9 \%)$ & $27(87.1 \%)$ & $95(84.8 \%)$ & \\
\hline $\mathrm{D} / \mathrm{E}$ & $26(31.7 \%)$ & $1(3.2 \%)$ & $14(12.5 \%)$ & \\
\hline \multicolumn{5}{|l|}{ Oral health } \\
\hline No oral health problem & $27(44.3 \%)$ & $12(38.7 \%)$ & $59(52.7 \%)$ & \multirow[t]{3}{*}{$p=0.012^{a}$} \\
\hline One oral health problem & $30(36.6 \%)$ & $7(22.6 \%)$ & $35(31.3 \%)$ & \\
\hline Two or three oral health problem & $25(30.5 \%)$ & $12(38.7 \%)$ & $18(16.1 \%)$ & \\
\hline
\end{tabular}

Table 1: Demographic and oral health data of the children ( $\chi^{2}$ test/Kruskal- Wallis test).

In order to evaluate the quality of life, all patients answered, at an interview, the questionnaire Autoquestionnaire Qualité de Vie Enfant Imagé (AUQEI) validated for Brazilian children by Assumpção Junior et al. Altogether, the questionnaire consisted of 26 questions on topics regarding family and social relationships, attitudes, health, body functions, and separation. Four main areas are addressed in 18 questions, namely: function (questions on school activities, meal, sleep, health care), family (questions on the children's perception of their parents and themselves), leisure (questions on holidays, birthday, and relationship with grandparents), and autonomy (questions on independence and relationship with friends).

Each answer was given a score ranging from 0 to 3 , where 0 means very unhappy and 3 very happy. The sum of these scores is the total for a given individual, which may vary from 0 to 78 . As a cutoff for this study, we used the average score obtained in the no-disease group. So, children with a score less or equal to this mean score were considered to have a reduced quality of life.
Immediately after AUQEI, the children responded, also during an interview, the short version of the Child Perception Questionnaire (short- $\mathrm{CPQ}_{11-14}$ ) [10] validated for Brazilian children by Torres et al. [11]. The questionnaire is composed of 16 questions to assess the impact of oral health on the quality of life.

Questions are organized into four subscales: oral symptoms, functional limitations, emotional well-being and social well-being with four questions each. The questions ask about the frequency of events in relation to the child's oral-facial condition in the previous three months. The response options are: "Never," "Once/Twice," "Sometimes", "Often" and "Everyday/Almost everyday". Each answer was given a score ranging from 0 to 4 , which added up can range from 0 to 64: the higher the scores the worse the oral-health-related quality of life Children who answer the short- $\mathrm{CPQ}_{11-14}$ and have a score other than 0 have negative impact on their quality of life related to oral health. 
Page 3 of 7

After answering the questionnaires, an oral clinical examination for all patients was made by a trained researcher. The oral examination was performed under natural light using only gauze and a tongue depressor. The presence of cavitated carious lesions in dentin, gingival disease, and oral soft tissue lesions, such as oral candidiasis, erythema linear, angular cheilitis, were observed and recorded.

The examined dental surfaces were given scores, according to Loe and Silness, following the criteria: normal gingiva, mild inflammation (slight change in color, slight edema, no bleeding on probing), moderate inflammation (redness, edema and glazing, bleeding on probing) and severe inflammation (marked redness and edema, ulceration, tendency to spontaneous bleeding) [12].

The DMFT/dmft index was determined by a trained using a mouth mirror,gauze, and probe. Only cavities extending to dentin were included in the caries indices (form primary and permanent teeth). Oral diseases such as angular cheilitis, erythema linear and oral candidiasis were performed clinically.

The children were classified according to their oral health as: no oral health problem, one oral health problem (carious lesion or gingival disease or oral lesion) and two or three oral health problems.

Data on clinical and immune classifications of the HIV-infected children as well as on drug therapy were obtained from medical records. The criteria used for case definition of AIDS were established by Centers for Disease Control and Prevention (CDC, 2008). The types of cancer were classified according to International Classification of Childhood Cancer [13].

\section{Statistical analysis}

The data was tabulated in a statistical software SPSS (SPSS 17.0, Chicado, IL, USA). The power of the selected samples was evaluated according to mean scores obtained in the questionnaires. For the
AUQEI questionnaire a power of $85.2 \%-70.9 \%$ was obtained and for the $\mathrm{CPQ}_{11-14}$, the power was $69.6 \%-64.2 \%$.

Statistical analysis was performed in two stages. Initially, a descriptive analysis was performed on the results, such as frequency, mean, median and standard deviation. After an analytical analysis was performed, patient demographic and clinical characteristics were compared using $\chi^{2}$ tests.

The scores obtained in the AUQEI and in the short-CPQ $\mathrm{CQ}_{11-14}$ were compared between groups using the Kruskal-Wallis test and MannWhitney tests, as the post hoc. For the analytical tests a statistical significance level of $5 \%$ was established.

\section{Results}

\section{Sample profile}

The average age of the children was $12.31(\mathrm{SD}=1.06)$, there were statistical differences when comparing the average age of the three groups (Table 1; Kruskal-Wallis-test, $\mathrm{p}=0.010$ ). Two children were excluded during questionnaire filling due inconsistent answers. Most of the children in the HIV- infected group were girls, while in the other groups were boys, however there was no statistical difference.

Most of the caregivers in the cancer (77.4\%) and no-disease (66.1\%) groups were the mothers of the children. In the HIV-infected group, $46.3 \%$ were the mothers. When comparing caregiver occupation $(\mathrm{p}=0.002)$, caregiver instruction $(\mathrm{p}=0.009)$ and economic classification $(\mathrm{p}=0.000)$, there were some statistical differences $\left(\chi^{2}\right.$ test $)$.

On analyzing the presence of oral health problems, it was observed that HIV-infected children and children with cancer presented more oral health problems than children with no-disease (Table $1 ; \chi^{2}$ test; $\mathrm{p}=0.012$ ).

\begin{tabular}{|l|l|l|l|l|}
\hline & HIV-infected children & Children with cancer & No-disease children & $\mathrm{p}$-value \\
\hline AUQEI score & $49.93( \pm 6.01)$ & $50.45( \pm 6.63)$ & $52.18( \pm 4.59)$ & $\mathrm{p}=0.011^{\mathrm{a}}$ \\
\hline Functions & $9.82( \pm 2.12)$ & $9.74( \pm 1.09)$ & $9.80( \pm 1.31)$ & $\mathrm{p}=0.918$ \\
\hline Family & $10.72( \pm 7.60)$ & $10.03( \pm 1.47)$ & $10.24( \pm 1.68)$ & $\mathrm{p}=0.307$ \\
\hline Leisure & $7.62( \pm 1.32)$ & $7.29( \pm 1.29)$ & $7.57( \pm 1.23)$ & $\mathrm{p}=0.390$ \\
\hline Autonomy & $7.87( \pm 1.94)$ & $7.51( \pm 1.24)$ & $3.03( \pm 1.84)$ & $\mathrm{P}<0.001^{\mathrm{a}}$ \\
\hline Short-CPQ $11-14$ score & $6.29( \pm 8.30)$ & $6.81( \pm 8.24)$ & $1.62( \pm 2.32)$ & $\mathrm{p}=0.043^{\mathrm{a}}$ \\
\hline Oral symptons & $2.87( \pm 3.00)$ & $3.48( \pm 3.68)$ & $1.32( \pm 2.21)$ & $\mathrm{p}=0.001^{\mathrm{a}}$ \\
\hline Functional limitations & $1.82( \pm 2.66)$ & $1.87( \pm 2.51)$ & $0.71( \pm 1.93)$ & $\mathrm{p}=0.337$ \\
\hline Emotional well-being & $1.05( \pm 2.44)$ & $1.19( \pm 2.39)$ & $0.17( \pm 1.03)$ & $\mathrm{p}=0.640$ \\
\hline Social well-being & $0.56( \pm 1.71)$ & $0.29( \pm 0.12)$ & & $\mathrm{p}=0.013^{\mathrm{a}}$ \\
\hline $\mathrm{a}=$ The result is significant at the 0.05 level. & & \\
\hline
\end{tabular}

Table 2: Means of the AUQEI score and factors, and short-CPQ $\mathrm{CP}_{114}$ score and subscales (Kruskal-Wallis test).

The types of cancer found in children were: Central Nervous System and miscellaneous intracranial and intraspinal neoplasms (8, 25.8\%); lymphomas and reticuloendothelial neoplasms (4, 12.9\%); germ cell tumors, trophoblastic tumors, and neoplasms of gonads (4,
12.9\%); leukemia, myeloproliferative diseases, and myelodysplastic diseases $(3 ; 9.7 \%)$ and other malignant epithelial neoplasms and malignant melanomas $(3,9.7 \%)$ 
Citation: Buczynski AK, Leão ATT, de Souza IPR (2015) Evaluation of Quality of Life in HIV-Infected Children and Children with Cancer.

Page 4 of 7

Also: retinoblastoma (2, 6.4\%); malignant bone tumors $(2,6.4 \%)$ soft tissue and other extraosseous sarcomas (2, 6.4\%); neuroblastoma and other peripheral nervous cell tumors $(1,3.2 \%)$; renal tumors $(1$, $3.2 \%)$ and hepatic tumors $(1,3.2 \%)$.

\section{Evaluation of quality of life}

HIV-infected children had the lowest score in the AUQEI, followed by children with cancer and the children with no-disease (Table 2; Kruskal-Wallis; $\mathrm{p}=0.011$ ), demonstrating that the first group had a lower quality of life.

\begin{tabular}{|c|c|c|c|c|}
\hline Item & HIV- infected children & Children with cancer & No- disease children & $p$-value \\
\hline When you stay at hospital & 0.59 & 0.58 & 0.96 & $p<0.000^{a}$ \\
\hline When you are away from your family & 0.85 & 1.61 & 1.35 & $p<0.000^{\mathrm{a}}$ \\
\hline When you go to a medical appointment & 1.72 & 1.23 & 1.88 & $p<0.000^{a}$ \\
\hline When you sleep out of your home & 1.67 & 1.61 & 2 & $p=0.002^{a}$ \\
\hline When your father or your mother talk about you & 1.71 & 2.16 & 1.89 & $p=0.005^{a}$ \\
\hline When you play alone & 1.51 & 1.23 & 1.65 & $\mathrm{p}=0.012^{\mathrm{a}}$ \\
\hline At the table, with the family & 2.21 & 2.1 & 2.35 & $p=0.044^{a}$ \\
\hline When your friends talk about you & 1.79 & 2.16 & 1.99 & $\mathrm{p}=0.058$ \\
\hline When you think about your mother & 1.79 & 2.26 & 1.91 & $p=0.060$ \\
\hline At night, when sleeping & 1.74 & 2.06 & 1.84 & $\mathrm{p}=0.081$ \\
\hline At night, when going to bed & 1.83 & 2.1 & 1.88 & $p=0.144$ \\
\hline $\begin{array}{l}\text { When someone asks you to show something you know how to } \\
\text { do }\end{array}$ & 2.23 & 2.06 & 2.26 & $p=0.208$ \\
\hline When you think about when you grow up & 2.24 & 2.13 & 2.13 & $\mathrm{p}=0.212$ \\
\hline When you are with your grandparents & 2.3 & 2.16 & 2.24 & $p=0.214$ \\
\hline When you think about your father & 1.59 & 1.94 & 1.8 & $\mathrm{p}=0.215$ \\
\hline When you receive your school grades & 2.07 & 1.87 & 2.02 & $p=0.224$ \\
\hline On your birthday & 2.71 & 2.61 & 2.69 & $\mathrm{p}=0.306$ \\
\hline When you practice any sports & 2.37 & 2.39 & 2.31 & $p=0.410$ \\
\hline At the classroom & 2.01 & 1.87 & 2.04 & $\mathrm{p}=0.411$ \\
\hline When you watch TV & 2.41 & 2.39 & 2.5 & $p=0.472$ \\
\hline If you have siblings, when you play with them & 2.27 & 2.39 & 2.37 & $p=0.624$ \\
\hline When you take medicines & 1.44 & 1.29 & 1.51 & $\mathrm{p}=0.687$ \\
\hline When playing, during school break & 2.43 & 2.48 & 2.53 & $\mathrm{p}=0.849$ \\
\hline When you do your homework & 1.67 & 1.72 & 1.74 & $\mathrm{p}=0.891$ \\
\hline During vacations & 2.63 & 2.58 & 2.64 & $\mathrm{p}=0.937$ \\
\hline When you see your own picture & 2.15 & 2.16 & 2.18 & $\mathrm{p}=0.951$ \\
\hline
\end{tabular}

Table 3: Individual mean scores regarding the AUQEI questionnaire (Kruskal- Wallis test).

The clinical and immunological classification of HIV-infected patients did not influence the score of AUQEI. Type of cancer and treatment received by children with cancer (chemotherapy, radiotherapy or surgery) did not influence the questionnaire score either.
As a cutoff, we used the mean score obtained in the no-disease group (52.13). On assessing the frequency of children with an AUQEI score greater than 52 , which indicated a good quality of life, we found that the HIV-infected group $(31 ; 37.8 \%)$ and the cancer group $(7$; $22.6 \%)$ had fewer children than the no-disease group $(69 ; 52.7 \%)\left(\chi^{2}\right.$ 
test; $\mathrm{p}=0.005$ ). Table 2 shows the average score obtained by each group as well as the mean score of the AUQEI factors.

Table 3 shows the mean score for each question of the AUQEI questionnaire. Items such as "When go to a medical appointment" $(\mathrm{p}<0.000)$ and "When stay at hospital" $(\mathrm{p}<0.001)$ had the lowest cores (Kruskal-Wallis Test) in the HIV-infected and cancer groups.

Considering the reliability of the questionnaire, the value for Cronbach's alpha for the AUQEI questionnaire was 0.660, showing good internal consistency.

\section{Assessment of oral health-related quality of life}

The cancer and HIV-infected groups had more impact on their oral health-related quality of life compared with the no-disease group (Table 2; Kruskal-Wallis, $\mathrm{p}=0.043$ ). More children in the HIV-infected and cancer groups presented a score for the short- $\mathrm{CPQ}_{11-14}$ different from 0 , which represents some impact in oral health-related quality of life, but there were no significance difference $\left(\chi^{2}\right.$ test; $\left.p=0.082\right)$. The oral symptoms subscale showed higher scores in the cancer group, followed by HIV-infected group and the no-disease group (Table 2; Kruskal-Wallis; $\mathrm{p}=0.001$ ).

The item "mouth sores" had a higher score in the cancer group $(\mathrm{p}=$ $0.010)$, while HIV-infected group had higher scores in "pain in teeth / mouth" ( $\mathrm{p}=0.023)$ (Kruskal-Wallis test). The score of other items of the short-CPQ $11-14$ questionnaire and the Kruskal-Wallis test are shown in Table 4.

The value for Cronbach's alpha for the short-CPQ $11-14$ questionnaire was 0.884 , indicating good internal consistency.

\section{Discussion}

Traditional definitions of health focus on illness and direct attention towards mortality and morbidity indicators. However, due to the road domains of life affected by a chronic illness, a quality of life perspective can be useful for several reasons. It can draw attention to other determinants of the health of adolescents and children, such as the importance of peers, family, attitudes, beliefs and education [14].

\begin{tabular}{|c|c|c|c|c|}
\hline Item & HIV- infected children & Children with cancer & No- disease children & p-value \\
\hline Bad breath & 0.37 & 0.81 & 0.11 & $\mathrm{P}<0.001^{\mathrm{a}}$ \\
\hline Food stuck in/between teeth & 0.57 & 0.97 & 0.37 & $p=0.004^{a}$ \\
\hline Felt shy/embarrassed & 0.17 & 0.35 & 0.06 & $p=0.005^{a}$ \\
\hline Mouth sores & 0.7 & 0.84 & 0.43 & $p=0.010^{a}$ \\
\hline Difficulty chewing & 0.56 & 0.48 & 0.25 & $p=0.012^{a}$ \\
\hline Avoied smiling/laughing & 0.27 & 0.19 & 0.08 & $p=0.017^{a}$ \\
\hline Pain in teeth/mouth & 1.23 & 0.87 & 0.71 & $p=0.023^{a}$ \\
\hline Teased/called names & 0.12 & 0.03 & 0.03 & $\mathrm{p}=0.122$ \\
\hline Argued with other children or your family & 0.07 & 0.01 & 0.03 & $p=0.261$ \\
\hline Slow chewing & 0.34 & 0.42 & 0.24 & $p=0.322$ \\
\hline Asked questions by other children & 0.1 & 0.06 & 0.06 & $p=0.458$ \\
\hline Concerned with what other think & 0.15 & 0.23 & 0.13 & $p=0.479$ \\
\hline Speech difficulty & 0.09 & 0.16 & 0.06 & $p=0.525$ \\
\hline Upset & 0.4 & 0.32 & 0.27 & $p=0.562$ \\
\hline Difficulty eating/drinking hot/cold foods & 0.83 & 0.94 & 0.77 & $p=0.593$ \\
\hline Felt irritable/frustated & 0.33 & 0.23 & 0.06 & $p=0.671$ \\
\hline
\end{tabular}

Table 4: Individual mean scores regarding the short- $\mathrm{CPQ}_{11-14}$ questionnaire (Kruskal-Wallis test).

Assessing quality of life of children with no chronic disease and those with chronic diseases is becoming even more important as the development in medical technology contributes to increased survival of the latter group, which may not mean the promotion of quality of life [15]. In the reviewed literature, we could not find studies comparing the quality of life of HIV-infected children, with children with cancer and with children without chronic infection. Also no studies were found that matched the assessment of quality of life with oral health-related quality of life in children. Thus, this study evaluated the quality of life and oral health-related quality of HIV-infected children and children with cancer.

To carry this out two generic instruments, AUQEI and short$C P Q_{11-14}$, which allow the comparison between groups and with children without the disease, were chosen. Manificat and Dazort [16] emphasizes that generic quality of life questionnaires are closer to the multidimensional concept of quality of life - this generic approach 
leads to a better knowledge of the strengths and the weakness of children living in specific conditions, from their own point of view.

Manificat et al. [17] and Manificat and Dazort [16] when describing the AUQEI, concluded that the questionnaire was able to distinguish between healthy children and ill children, such as HIV-infected. This study showed that the presence of HIV infection and cancer caused a negative impact on the quality of life in children, since they obtained average and median AUQEI scores lower than the no-disease group. Moreover, the values found in our study for the three groups were lower than those found in other studies of patients with chronic diseases. Manificat and Dazort [16] in the validation study of the AUQEI obtained a score of 54.34 for healthy children, 53.04 for children living with a chronic disease and 53.03 for children living in a difficult context (somatic, social or psychological). In another study by Kuczynski et al., the mean scores of AUQEI for children with acute lymphatic leukemia, children with juvenile rheumatoid arthritis, and healthy children were, respectively, 54.64, 57.18, and 58.43, which are higher scores than the ones found in this study. Thöni et al. [18] found a score of 54.6 for HIV-infected children and healthy children.

Assumpção Junior et al. [19] established in the validation study the cutoff of 48 for Brazilian children, which indicate that children with AUQEI score greater than this value have a good quality of life. However, this cutoff was established for children without health or social factors that could jeopardize the index expression, and may not be valid for our children. For this study, we determined the cutoff as the average score (52) obtained in the questionnaire by the no-disease group. We observed that more children in the HIV-infected group and in the cancer group presented a score equal or less than 52, indicating a bad quality of life.

AUQEI questionnaire items directly related to the presence of a chronic illness in childhood such as "go to a medical appointment" and "stay at the hospital" had significant values in patient groups. This is due to the fact that treatment of HIV infection and cancer is long, requiring, in many cases, frequent hospitalizations, recurrent medical visits and continuous use of medicines.

It was observed that families with HIV-infected children were different from those with children with cancer. There was more unemployment in the families that had children with cancer which can be explained by the fact that their parents often had to leave their jobs due to the long treatment imposed by the disease. Nevertheless, this group showed a higher level of education and socioeconomic status. Unlike the group of HIV-infected children, who presented a lower level of education and socioeconomic status, which can be explained by the fact that the disease is more, frequent in groups of people in a low socioeconomic and cultural level [20-23].

It is suggested that the oral health-related quality of life of children with cancer can be explained by many factors. Children that were under long-term cancer treatment commonly present oral alterations, such as decreasing in salivary flow rate and xerostomia, flavor alterations, and also dental caries. Another point is the limitation of oral health after cancer treatment [24]. These are factors that can contribute with decrease of quality of life in children with this condition.

As a limitation of the current study, can be pointed out the candidiasis diagnostic. Generally, the diagnosis of oral candidiasis is fundamentally clinical. However, microbiological techniques are used when the clinical diagnosis needs to be confirmed when absence of clinical manifestations is compatible with oral candidiasis. In our study, the diagnosis was performed clinically, consisting in a limitation of the study, since the disease can be underscored. As well as the time of treatment for HIV and cancer, that was at least 3 months, but even besides these inclusion criteria, there was varied time of treatment (more than 3 months).

Family functioning in the two diseases is also quite distinct. AUQEI items as "think of his father" and "think about mother," showed higher values in the case of children with cancer and lower in the group of HIV- infected children, although no statistical difference was found. This difference is mainly due to the fact that children with HIV are often from dysfunctional families, and whose father/mother, if alive, may be unable to take care of this child [21]. As in childhood cancer, mother and/or father are usually responsible for the care and treatment of the child, creating a closer and even dependent relationship, which may explain why this group also had a lower score for the factor Autonomy.

In terms of oral health, most HIV-infected children and children with cancer had some oral health problems. The two groups had similar values for the short-CPQ ${ }_{11-14}$ score, but higher than the nodisease group. Likewise, the illness groups had a higher score for the oral symptoms subscale, demonstrating that problems such as pain and discomfort and the presence of mouth sores can impact on their oral health-related quality of life. Foster Page et al. [25] emphasize that children with caries cavities and oral lesions are more likely to experience pain and difficulty in chewing. They are also more likely to become upset or concerned with their dental health, which can cause more serious impacts on their quality of life.

Some studies have demonstrated a direct relationship between the socioeconomic level and quality of life [26-29]. In our study, HIVinfected children presented a low socioeconomic status and also presented high impact in the oral health related quality of life. Piovesan et al. [27] suggested that poor socioeconomic standings and poor dental status have a negative impact on children's oral healthrelated quality of life. Children from low socioeconomic levels are more likely to be exposed to many risk factors affecting oral health, and that oral health contributes significantly to the quality of life not only considering functional domains but also psychological and social [26] Sanders et al. [28] highlighted that a low educational level may lead to reduced income, unemployment and poor occupational status; these conditions influence health behaviors and self- rated oral health. And also, a previous study suggested that oral health outcomes are influenced by the mother's education level [29].

The treatment for HIV-infected children reduce oral lesions, such as candidiasis, improving the quality of life [30] since fewer oral lesions are found in children under current drug therapy regimens for HIV infection. These therapies aim to reduce viral load as much as possible, promoting immunologic protection, which reduces the potential risk of opportunistic infection. Otherwise, treatment for HIV-infected children can cause discomfort caused by medication side effects. In the case of cancer treatment, as discussed above, promotes some oral alterations that can influence the quality of life at the moment of therapy, such as such as decreasing in salivary flow rate and xerostomia, flavor alterations. Although, at the moment of treatment for both diseases, the treatments can provide some discomfort, the results will promote a better life expectation and a better quality of life for entire life. 


\section{Conclusion}

The results showed that HIV infection and cancer in childhood can cause a negative impact on quality of life and oral health-related quality of life. It is important that health professionals become more aware to intervene, in the case of these children, not only to add more years to life, but also more quality of life to the years lived.

\section{Acknowledgements}

The authors would like to thank the CNPq-Brazil (National Counsel of Technological and Scientific Development) for its financial support.

\section{References}

1. Elting LS, Avritscher EB, Cooksley CD, Cardenas-Turanzas M, Garden AS, et al. (2008) Psychosocial and economic impact of cancer. Dent Clin North Am 52: 231-252.

2. Eiser C, Havermans T, Pancer M, Eiser JR (1992) Adjustment to chronic disease in relation to age and gender: mothers' and fathers' reports of their childrens' behavior. J Pediatr Psychol 17: 261-75.

3. Eiser C, Morse R (2001) Can parents rate their child's health-related quality of life? Results of a systematic review. Qual Life Res 10: 347-357.

4. Garvie PA, Lawford J, Banet MS, West RL (2009) Quality of life measurement in paediatric and adolescent populations with HIV: a review of the literature. Child Care Health Dev 35: 440-453.

5. Ryerson CJ, Vittinghoff E, Ley B, Lee JS, Mooney JJ, et al. (2014) Predicting survival across chronic interstitial lung disease: the ILD-GAP model. Chest 145: 723-728.

6. Vollmer WM, Wahl PW, Blagg CR (1983) Survival with dialysis and transplantation in patients with end-stage renal disease. N Engl J Med 308: 1553-1558.

7. Hicks MJ, Flaitz CM, Carter AB, Cron SG, Rossmann SN, et al. (2000) Dental caries in HIV-infected children: a longitudinal study. Pediatr Dent 22: 359-364

8. Acs G, Lodolini G, Kaminsky S, Cisneros GJ (1992) Effect of nursing caries on body weight in a pediatric population. Pediatr Dent 14 302-305.

9. Gift HC, Reisine ST, Larach DC (1992) The social impact of dental problems and visits. Am J Public Health 82: 1663-1668.

10. Jokovic A, Locker D, Guyatt G (2006) Short forms of the Child Perceptions Questionnaire for 11-14-year-old children (CPQ11-14): development and initial evaluation. Health Qual Life Outcomes 4: 4.

11. Torres CS, Paiva SM, Vale MP, Pordeus IA, Ramos-Jorge ML, et al. (2009) Psychometric properties of the Brazilian version of the Child Perceptions Questionnaire (CPQ11-14) - short forms. Health Qual Life Outcomes 7: 43

12. Loe H, Silness J (1963) Periodontal disease in pregnancy. I. Prevalence and severity. Acta Odontol Scand 21: 533-551.

13. Steliarova-Foucher E, Stiller C, Lacour B, Kaatsch P (2005) Internationa Classification of Childhood Cancer, third edition. Cancer 103: 1457-1467.
14. Raphael D (1996) Determinants of health of North-American adolescents: evolving definitions, recent findings, and proposed research agenda. J Adolesc Health 19: 6-16.

15. Eiser C, Jenney M (2007) Measuring quality of life. Arch Dis Child 92 348-350.

16. Manificat S, Dazord A (2002) Infant, child and adolescent quality of life: surveys performed in a European context. Expert Rev Pharmacoecon Outcomes Res 2: 589-596.

17. Manificat S, Dazord A, Cochat P, Nicolas J (1997) [Evaluation of the quality of life in pediatrics: how to collect the point of view of children].Arch Pediatr 4: 1238-1246.

18. Thöni GJ, Lalande M, Bachelard G, Vidal P, Manificat S, et al. (2006) [Quality of life in HIV-infected children and adolescents under highly active antiretroviral therapy: change over time, effects of age and familial context]. Arch Pediatr 13: 130-139.

19. Assumpção Junior FB KE, Sprovieri MH, Aranha EM (2000) Quality of life evaluation scale (AUQEI--Autoquestionnaire Qualite de Vie Enfant Image). Validity and reliability of a quality of life scale for children 4 to 12 years-old. Arq Neuropsiquiatr 58: 119-127.

20. Broder HL, Slade G, Caine R, Reisine S (2000) Perceived impact of oral health conditions among minority adolescents. J Public Health Dent 60: 189-192.

21. Falloon J, Eddy J, Wiener L, Pizzo PA (1989) Human immunodeficiency virus infection in children. J Pediatr 114: 1-30.

22. Phaladze NA, Human S, Dlamini SB, Hulela EB, Hadebe IM, et al. (2005) Quality of life and the concept of "living well" with HIV/AIDS in subSaharan Africa. J Nurs Scholarsh 37: 120-126.

23. Wiener L, Mellins CA, Marhefka S, Battles HB (2007) Disclosure of an HIV diagnosis to children: history, current research, and future directions. J Dev Behav Pediatr 28: 155-166.

24. Wogelius P, Rosthøj S, Dahllöf G, Poulsen S (2011) Oral health-related quality of life among survivors of childhood cancer. Int J Paediatr Dent 21: 465-467.

25. Foster Page LA, Thomson WM, Jokovic A, Locker D (2005) Validation of the Child Perceptions Questionnaire (CPQ 11-14). J Dent Res 84: 649-652.

26. Goursand D, Paiva SM, Zarzar PM, Ramos-Jorge ML, Cornacchia GM, et al. (2008) Cross-cultural adaptation of the Child Perceptions Questionnaire 11-14 (CPQ11-14) for the Brazilian Portuguese language. Health Qual Life Outcomes 6: 2.

27. Piovesan C, Antunes JL, Guedes RS, Ardenghi TM (2010) Impact of socioeconomic and clinical factors on child oral health-related quality of life (COHRQoL). Qual Life Res 19: 1359-1366.

28. Sanders AE, Spencer AJ (2005) Childhood circumstances, psychosocial factors and the social impact of adult oral health. Community Dent Oral Epidemiol 33: 370-377.

29. Traebert J, Guimarães Ldo A, Durante EZ, Serratine AC (2009) Low maternal schooling and severity of dental caries in Brazilian preschool children. Oral Health Prev Dent 7: 39-45.

30. Tappuni AR, Fleming GJ (2001) The effect of antiretroviral therapy on the prevalence of oral manifestations in HIV-infected patients: a UK study. Oral Surg Oral Med Oral Pathol Oral Radiol Endod 92: 623-628. 